\title{
THE POSITION AND COMPOSITION OF PEBBLES IN TERRACE OF NORTH-WEST SHORE OF CHOKRAK LAKE IN STRATIGRAPHIC COLUMN
}

\section{A.D. Naumenko}

\section{ПОЛОЖЕНИЕ И СТРОЕНИЕ ГАЛЕЧНИКОВ ТЕРРАСЫ СЕВЕРО-ВОСТОЧНОГО БЕРЕГА ЧОКРАКСКОГО ОЗЕРА В СТРАТИГРАФИЧЕСКОМ РАЗРЕЗЕ}

\section{А.Д. Науменко}

In article are presented lithologic description and stratigraphic position of pebble terrace, which an author find in summer 2008. The terrace is located in north-west shore of Chokrak lake $200 \mathrm{~m}$ from famous Karangat terrace.

Key words: stratigraphic position, Karangat, terrace, pebbles.

В статье, по предварительным данным полевых исследований лета 2008 года, приведено литологическое описание и обосновано стратиграфическое положение найденной автором галечниковой террасы, которая находится на северовосточном берегу озера Чокрак (в 200м на восток от знаменитой карангатской террасы)

Ключевые слова: стратиграфический разрез, карангат, терраса, галечник.

Положение отложений четвертичной системы оз. Чокрак на границах древнеэвксинско-узунларского и карангатского стратиграфических уровней определяет большой интерес к их строению, условиям залегания и стратиграфическому подразделению. Последнее является одним из дискуссионных в стратиграфии четвертичных отложений. Объясняется это, во-первых, - недостаточной изученностью стратиграфического разреза, а, во-вторых, - отсутствием надежных критериев для сопоставления отложений с одновозрастными континентальными образованиями.

Работа проводилась на севере Керченского полуострова, в пределах северо-восточного берега Чокракского озера. Множество опубликованных наблюдений отложений террас, находящихся на его берегах, относится к естественным обнажениям, открывающимся в береговых обрывах озера и скважинам, заложенным в непосредственной близости от них. В июле 2008 года автором была обследована тыловая часть террасы, фигурирующая в литературных источниках под названием «терраса восточного берега оз. Чокрак», в месте примыкания ее к коренному склону.

Полевые наблюдения показали, что в двухстах метрах восточнее описанной П.В. Федоровым [2] террасы и гипсометрически выше ( $\approx$ м) расположено тело рыхлых галечников, разрез которых представлен в таблице 1. Исследование склона, на котором располагаются террасы, с м. Зюк (рисунок 1) подтвердило предположение, что на нем развиты несколько поверхностей выравнивания: нижняя из которых отвечает верхнему уровню террасы карангатского возраста, лежащий над ней уровень отвечает положению кровли галечниковой террасы и верхний, который отождествляется с уровнем высокой террасы (25-30 м над уровнем моря), возвышающейся над поселком Курортное.

Поверхность выравнивания галечниковой террасы прислонена к абразионному уступу высокой террасы (рисунок 1 , профиль по линии А - В).

В свою очередь, поверхность выравнивания карангатской террасы прислонена к уступу галечниковой террасы. Из этого следует, что поверхность выравнивания галечниковой террасы древнее карангатской, но моложе высокой.

Об этом же свидетельствует и вскрытая в краевом уступе галечниковой террасы дислокация гравитационного оползания, накрывающая верхний уровень карангатской террасы. По всей видимости, мелкая складка была сформирована вследствие абразионных процессов, формировавших эту поверхность.

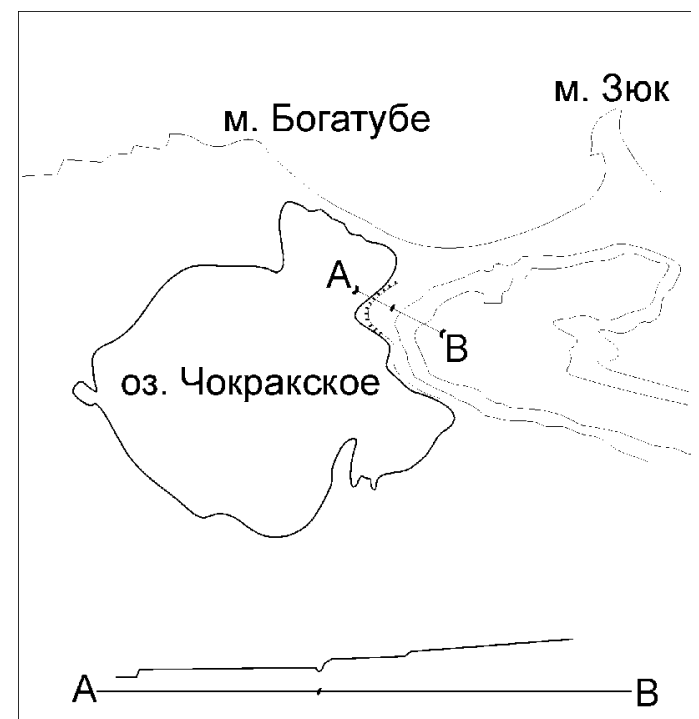

Pис. 1. 
Из описания А.Д. Архангельского и Н.М. Страхова [1] (1938) следует, что узунларские отложения здесь были вскрыты шурфом. П.В. Федоров [2] на западном берегу соленого Чокракского озера проследил взаимоотношения между древнеэвксинскими и карангатскими слоями (см. табл. 4). В северной части западного берега озера слой 4 содержит смешанную фауну, состоящую из карангатских форм и раковин, вымытых из древнеэвксинских слоев. Отчетливо видно, что слой 4 залегает непосредственно на размытой поверхности древнеэвксинских слоев (слой 5), имевших здесь видимую мощность до 2 м. Выпадение из разреза суглинков, развитых в соседнем обнажении выше древнеэвксинских песков, вызвано, по-видимому, более энергичной абразией карангатского моря на этом участке.

Разрез карангатских отложений северо-восточного берега оз. Чокрак представлен в табл. 2, по П.В. Федорову [2]. Автор отмечает, что, мощность карангатских отложений на восточном берегу озера увеличивается. А также то, что здесь:

- во-первых, обнажается самая нижняя часть карангатских прибрежных отложений - рыхлые песчаники слоя 6, на которых с некоторым размывом лежат грубые ракушечники - устричники слоя 5 и все лежащие выше осадки;

-во-вторых, эти прибрежные отложения (слои 2-5) сами отчетливо делятся на три части: верхние - грубые прибрежные ракушечники (слой 3), средние - рыхлые песчаники (слой 4) и нижние грубые ракушечники и устричные банки (слой 5).

П.В. Федоров [2] считает, что такое чередование прибрежных осадков различного механического состава, их цементация и взаимное замещение по простиранию отражают разные фазы развития карангатской трансгрессии и обусловлены изменением рельефа прибрежной части дна. Видимо, как и в береговом обнажении севернее Тобечикского озера, это чередование указывает на первоначальную фазу трансгрессии (слой 6), после которой наступила вторая фаза - более глубокое вторжение моря в пределы суши (абразия берега - следовательно, обилие обломочного материала), когда береговая линия (слои $3,4,5$ ) три раза перемещалась. Следовательно, самые нижние слои отложений террасы на восточном берегу Чокракского озера являются древнеэвксинскими. Однако полученные в 2007 и 2008 гг. данные заставляют усомниться в правильности такой интерпретации.

В 2007 г В.Н. Шелкопляс и Т.Ф. Христофорова опубликовали данные по бурению карангатских террас в этом районе [3], и показали характер строения толщи четвертичных отложений (см. табл. 3). Здесь ракушечный конгломерат слоя 2 табл. 3 сопоставим со слоями 3 и 2 табл. 2, однако возраст этих отложений, по данным [3], составляет 25 тыс. лет и не является карангатским. В тоже время отложения слоя 4 (табл. 2) и слоя 3 (табл. 3), судя по литологическим индикативным признакам, нужно признать образованиями дюн. Не должно вводить в заблуждение наличие в этих отложениях целых половинок раковин моллюсков карангатского моря. Подобную картину можно наблюдать и в современных дюнах по берегам Керченского пролива, куда эти ископаемые поставляются сильными порывами ветра от места захлеста штормовой волны. Причем, чем целее раковина, тем больше ее парусность, тем больше вероятность попадания ее в тело дюны. Этот уровень можно считать временем посткарангатской регрессии.

Таким образом, лежащие ниже несогласия осадки слоев 5 и 6 (табл. 3), коррелируемые со слоем 5 (табл. 2) и со слоями 2-10 (табл. 1), представляют собою верхнюю часть карангатского разреза, в низах которой залегают биогермы. По мнению автора настоящей статьи, появление биогерм в разрезе может служить своего рода маркирующим горизонтом, помогающим отделить опресненную фазу бассейна от собственно морской фазы, так как ниже этих слоев располагаются глинистые пески (табл. 1) слоя 11, ил - слоя 12, дресва и мелкие гальки (до 10 мм) карбонатных пород в заполнителе из ломаной ракушки и глины - слоя 13, дресва и мелкие гальки (до 10 мм) карбонатных пород в заполнителе из ломаной ракушки без глины - слоя 14. Причем, комплекс фауны этих отложений соответствует переходу нижнекарангатских отложений в верхнекарангатские.

Что касается условий залегания этого геологического образования, то необходимо отметить эрозионное несогласие в основании галечника, а также пологое падение его контакта с подстилающими породами в юго-западном направлении, под углом около $3^{\circ}$. Представляется, что галечниковая терраса залегает на коре выветривания, развитой по пролювиальным отложениям этого склона (слой 7, табл. 1). 
Таблица 1. Разрез галечниковой террасы на северо-восточном берегу оз. Чокрак

\begin{tabular}{|c|c|c|c|}
\hline 1. & $\begin{array}{l}\text { Суглинки покровные, желтоватые с почвенным горизонтом в верхней } \\
\text { части. }\end{array}$ & \multirow{6}{*}{ 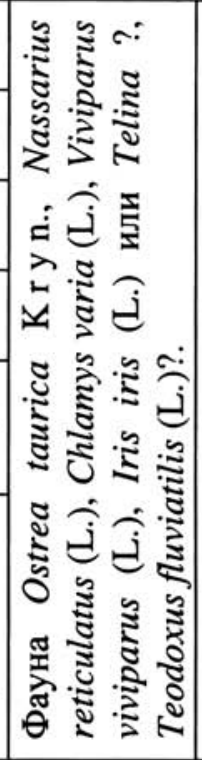 } & \multirow{3}{*}{$\begin{array}{l}\approx 0,3- \\
1,5 \mathrm{M} \\
\approx 0,2 \mathrm{M} \\
\approx 0,3 \mathrm{M}\end{array}$} \\
\hline 2. & $\begin{array}{l}\text { Мелкий галечник с детритусовым песчанистым заполнителем } \\
\text { буроватого цвета. }\end{array}$ & & \\
\hline 3. & $\begin{array}{l}\text { Прослой крупных раковин Ostrea taurica K r у п. частично окатанных, } \\
\text { не сцементированных. }\end{array}$ & & \\
\hline 4. & $\begin{array}{l}\text { Галечник со средней размерностью галек } \approx 5 \text { см и детритусовым } \\
\text { песчанистым заполнителем буроватого цвета. }\end{array}$ & & $\approx 0,6 \mathrm{M}$ \\
\hline 5. & $\begin{array}{l}\text { Грубый галечник с детритусовым песчанистым заполнителем } \\
\text { содержит хорошо окатанную гальку около } 15 \text { см в диаметре, цвет } \\
\text { бурый. }\end{array}$ & & $\approx 1 \mathrm{M}$ \\
\hline 6. & $\begin{array}{l}\text { Глыбово-валунный галечник с детритусовым песчанистым } \\
\text { заполнителем. Глыбы и плохо окатанные валуны маркируют своим } \\
\text { расположением косую слоистость. Падение косых слоев к подошве } \\
\text { горизонта } \approx 20^{\circ} \text { Ц Цвет отложений бурый. Слой залегает на размытой } \\
\text { поверхности, по которой, согласно с ее простиранием, лежат } \\
\text { отдельные раковины Solen, Chlamys glabra } \\
\text { (L.) отличной coхранности. }\end{array}$ & & $\approx 1 \mathrm{M}$ \\
\hline 7. & $\begin{array}{l}\text { Суглинок дресвяный, с крупными обломками }(5 \text { на } 20 \text { см) чокракских } \\
\text { известняков, выстилающих слой вдоль поверхности напластования. } \\
\text { Цвет зеленовато-серый. }\end{array}$ & $\approx 0,05 \mathrm{M}$ & \\
\hline 8. & $\begin{array}{l}\text { Сильно перетертый ракушечный детрит без присутствия глинистых } \\
\text { фракций, имеющий параллельную слоистость (до } 7 \text { слойков на } 10 \text { см } \\
\text { мощности). Цвет пропластка палевый. }\end{array}$ & $\approx 0,1 \mathrm{M}$ & \\
\hline 9. & $\begin{array}{l}\text { Песок очень глинистый с немногочисленными кусочками дресвы } \\
\text { карбонатных пород, а также с фауной двустворчатых малюсков (in } \\
\text { situm). Цвет зеленовато-серый с незначительным рыжеватым } \\
\text { оттенком. Cardium edule L., Nassarius reticulatus (L.), Corbula } \\
\text { mediterranea (Costa) или Abra ovata (Phil)?. }\end{array}$ & $\approx 0,25 \mathrm{M}$ & \\
\hline 10. & $\begin{array}{l}\text { Ракушечник устричной банки с гальками, грубообломочный. } \\
\text { Раковины хорошей сохранности, сцементированные известковым } \\
\text { цементом, на внутренней поверхности имеют остатки перламутрового } \\
\text { слоя. Цвет ракушечника белый. Cardium edule L., Ostrea taurica } \\
\text { K ry n., Nassarius reticulatus (L.). }\end{array}$ & $\approx 0,25 \mathrm{M}$ & \\
\hline 11. & $\begin{array}{l}\text { Глинистый песок из раковинного детрита с мелкой дресвой и галькой } \\
\text { (до } 5 \text { мм) карбонатных пород, с фауной (in situm). Цвет отложений } \\
\text { зеленовато-палевый, светлый. Chione gallina, Cardium edule L. }\end{array}$ & $\approx 0,5 \mathrm{M}$ & \\
\hline 12. & $\begin{array}{l}\text { Ил алевритовой размерности с фауной двустворчатых малюсков (in } \\
\text { situm). Цвет светло-зеленый.Gastrana phragilis, Nassarius reticulatus } \\
\text { (L.), Mytilaster lineatus (G m. In L.), Bittium reticulatum (Costa) } \\
\text { единичный, }\end{array}$ & $\approx 0,05 \mathrm{M}$ & \\
\hline 13. & $\begin{array}{l}\text { Дресва и мелкие гальки (до } 10 \text { мм) карбонатных пород в заполнителе } \\
\text { из ломаной ракушки и глины, снизу вверх глинистость значительно } \\
\text { возрастает. Цвет отложений зеленовато-серый. Mytilaster lineatus (G } \\
\text { m. In L.)?. Cardium edule L., Bittium reticulatum (Costa), Nassarius } \\
\text { reticulatus (L.), Paphia senescens (Coc.), Teodoxus fluviatilis (L.)?. и дp. }\end{array}$ & $\approx 0,45 \mathrm{M}$ & \\
\hline 14. & $\begin{array}{l}\text { Дресва и мелкие гальки (до } 10 \text { мм) карбонатных пород в заполнителе } \\
\text { из ломаной ракушки. Детрит хорошо промыт. Цвет отложений } \\
\text { зеленовато-палевый, светлый. }\end{array}$ & $\begin{array}{l}\approx 0,25 \mathrm{м} \\
\text { Разрез ниж } \\
\text { вскрыт }\end{array}$ & ке не \\
\hline
\end{tabular}


Таблица 2. Разрез карангатской террасы на восточном берегу оз. Чокрак [2]

\begin{tabular}{|c|c|c|}
\hline 1. & Суглинки покровные, желтоватые и светло серые. & $2-3 \mathrm{M}$ \\
\hline 2. & Рыхлый детритусовый песчаник буровато серого цвета. & $1 \mathrm{M}$ \\
\hline 3. & $\begin{array}{l}\text { Грубый ракушечник и конгломерат из хорошо окатанной гальки, крупных } \\
\text { раковин Ostrea taurica K r y n., Tapes calverti N e w t, Cardium edule L., } \\
\text { Venus gallina L., Mytilus galloprovincialis L a m., Solen, скрепленных } \\
\text { известняково детритусовым цементом, а в промежутках заполненных } \\
\text { ракушечниковой дресвой. }\end{array}$ & $1.5-2 \mathrm{M}$ \\
\hline 4. & $\begin{array}{l}\text { Рыхлый розовато-желтый детритусовый песчаник с Tapes calverti N e w t., } \\
\text { Cerithium vulgatum B r u g., Cardium tuberculatum L. и др. }\end{array}$ & $1-1,5 \mathrm{~m}$ \\
\hline 5. & $\begin{array}{l}\text { Грубый, прочный ракушечник, переходящий в устричные банки, } \\
\text { содержит хорошо окатанную гальку с прослоями грубых детритусовых } \\
\text { песчаников, фауна - Ostrea taurica } \mathrm{K} \text { r y n, Mytilus galloprovincialis } \mathrm{L} \text { a m., } \\
\text { Pecten ponticus M I1 и дp. Залегает с размывом на подстилающих осадках. }\end{array}$ & $1,5-2 \mathrm{~m}$ \\
\hline 6. & $\begin{array}{l}\text { Рыхлый светло-желтый и палевый детритусовый песчаник с Solen } \\
\text { marginatus P e n n., Cardium edule L., Venus gallina L., Mytilus } \\
\text { galloprovincialis L a m., Cerithium vulgatum B r ug., Pholas dactulus L. и дp. } \\
\text { Видимая мощность }\end{array}$ & $1 \mathrm{M}$ \\
\hline \multicolumn{3}{|c|}{ Ниже - осыпь } \\
\hline & них песчаников (слой 6) & \\
\hline
\end{tabular}

Таблица 3. Разрез скважины 6/86, пробуренной на восточном берегу озера Чокрак, в 15 м от бровки террасы [3]

\begin{tabular}{|c|c|c|}
\hline 1. & $0,0-0,3 \mathrm{~m}$ & Современная почва. \\
\hline 2. & $\begin{array}{l}0,3-4,0 \text { м } \\
\text { КТЛ } 34 / 8625 \text { т.л. }\end{array}$ & $\begin{array}{l}\text { Переслаивание песка мелко- и разнозернистого, с отдельной } \\
\text { галькой и гравием. Пески косослоистые. Много фауны } \\
\text { моллюсков: Pecten ponticus Mull., Ostrea Tairica Kryp., Venus } \\
\text { gallina L., Cardium edule C., Solen, Mytilus Galloprovincialis } \\
\text { Lam. }\end{array}$ \\
\hline 3. & $4,0-6,7 \mathrm{~m}$ & $\begin{array}{l}\text { Песок темно-бурый, мелко- и тонкозернистый, слоистый и } \\
\text { косослоистый с фауной: Didacna pallasi Prav., Corbicula } \\
\text { fluminalis Mull., Cardium edule L., Venus gallina L. и др. }\end{array}$ \\
\hline 4. & $\begin{array}{l}6,7-8,5 \mathrm{~m} \\
\mathrm{Q}_{\mathrm{III}}\end{array}$ & $\begin{array}{l}\text { Песок гравелистый с галькой (базальный горизонт). } \\
\text { В нижней части на глубине } 8,5 \text { м конгломерат-ракушечник. } \\
\text { Фауна: Cerichium vuegatum Brug., Didacna nalivkini Wass., } \\
\text { Didacna pontocaspia Pavl., Viviparus, Corbicula fluminalis Mull. }\end{array}$ \\
\hline 5. & $8,5-9,5 \mathrm{~m}$ & $\begin{array}{l}\text { Песок грубозернистый и разнозернистый, сцементирован до } \\
\text { ракушечника с фауной Cardium edule L., Venus gallina L., } \\
\text { Mytilus Galloprovincialis Lam. }\end{array}$ \\
\hline 6. & $9,5-10,0 \mathrm{M}$ & Галечник светло-серый, плотный, биогермы. \\
\hline 7. & $10,0-15,4 \mathrm{~m}$ & $\begin{array}{l}\text { Суглинок желтовато-бурый, легкий, в середине песчаный, } \\
\text { прослои до } 5 \text { см, сильно карбонатный, с галькой. }\end{array}$ \\
\hline 8. & $15,4-17,7 \mathrm{~m}$ & Глина темно-серая, пластичная, жирная, вязкая, карбонатная. \\
\hline
\end{tabular}

Еще А.Д. Архангельский и Н.И. Страхов отмечали, что галечники с палюдиновой фауной подстилаются узунларскими отложениями. Позднее (1978) П.В. Федоров, описывая разрез чокракской террасы, отмечал наличие перерыва между карангатскими, узунларскими и древнеэвксинскими отложениями. Однако автору статьи не удалось наблюдать указанного в работе [2] перерыва. Возможно, будущие работы, предусматривающие расчистку нижней части разреза, позволят решить эту проблему. Зато отчетливый перерыв наблюдается в разрезе выше слоя с биогермами. 
Таблица 4. Разрез западного берега озера Чокрак [2]

\begin{tabular}{|c|c|c|}
\hline 1. & Почвенный слой & $0,5 \mathrm{M}$ \\
\hline 2. & Суглинки неслоистые, лессовидные, желтовато-палевые & $1,5 \mathrm{M}$ \\
\hline 3. & $\begin{array}{l}\text { Пески косослоистые, переполненные ракушей Pecten ponticus Mil., Ostrea } \\
\text { taurica Kryn., Solen marginatus Perm, Venus gallina L., Donax julianae Krvn, } \\
\text { Tapes calverti Newt, Centhiolum reticulatum L., и др } \\
\text { Ниже эти пески постепенно грубеют и переходят в подстилающий слои }\end{array}$ & $1,5 \mathrm{M}$ \\
\hline 4. & $\begin{array}{l}\text { Пески крупнозернистые, косослоистые, переходящие в ракушечник, под } \\
\text { стилаемый мелкой галькой. В ракушечнике, кроме фауны перечисленной } \\
\text { в слое } 3 \text {, а также и ряда других средиземноморских форм - Centhium } \\
\text { vulgatum Brug, Centhium ponticum Mil, встречаются частично окатанные и } \\
\text { явно вымытые из подстилающих отложений Didacna nalwkini Wass, D } \\
\text { pontocaspia PaLL, D cf pallasi Prav и пресноводные Paludina, Corbicula } \\
\text { fluminalis Mull, преобладающие в общей масcе ракуши. Галечник } \\
\text { подошвы этого слоя лежит на размытой поверхности лежащего ниже } \\
\text { слоя }\end{array}$ & $1.5 \mathrm{M}$ \\
\hline 5. & Суглинки неслоистые, желтовато серые & $1 \mathrm{M}$ \\
\hline 6. & Суглинки неслоистые, серые & $1 \mathrm{M}$ \\
\hline 7. & $\begin{array}{l}\text { Пески глинистые, слоистые, буровато желтые, с фауной Didacna nalivkini } \\
\text { Wass, D. pallasi Prav, Corbicula fluminalis } \text { Mull, Paludina (последние две } \\
\text { формы преобладают) }\end{array}$ & $\begin{array}{l}\text { Видимая } \\
\text { мощность } \\
2 \text { м }\end{array}$ \\
\hline
\end{tabular}

В разрезе, расположенном в 200 м к западу от галечниковой террасы и приведенном в работе [3] (табл. 3), указано, что на глубине 9,5 м залегают галечники с биогермами, которые на глубине 10,0 м подстилаются суглинком желтовато-бурым, легким, в середине песчаным (прослои до 5 см), сильно карбонатным, с галькой. Этот слой, мощностью 5,4 м, по литологическим признакам хорошо соотносится с образованиями развитых пролювиальных шлейфов, образующихся в нижних частях пологих склонов в акватории лимана.

По нашим данным (табл. 1), ниже мелкого галечника с биогермами слоя 10 лежат глинистый песок зеленовато-палевый, светлый, из раковинного детрита, с мелкой дресвой и галькой (до 5 мм) карбонатных пород, с фауной (in situm) Chione gallina, Cardium edule $L$ - слоя 11. Разница в описаниях вполне объяснима различием в объекте наблюдения - в работе [3] изучался влажный керн, а наше описание сделано на сухом обнажении. Появление в разрезе Chione gallina свидетельствует о том, что трансгрессирующее, последовательно осолоняющееся карангатское море достигло солености 10 (12)\%о. При этом смена последовательности осадков в сторону увеличения их крупности (ил - глинистый песок - песок глинистый - мелкий галечник с устричной банкой), а затем в сторону уменьшения и снова увеличения (мелкий галечник с устричной банкой - песок очень глинистый, с немногочисленными кусочками дресвы - дюнный песок - пролювий) указывает на тенденцию к обмелению водоема, вслед за которой последовало углубление, а затем быстрое осушение. Такое изменение в осадочном разрезе с точки зрения палеогеографии района может быть истолковано следующим образом.

Трансгрессия карангатского моря происходила медленно, со скоростью немного отстающей от скорости осадконакопления в лиманах, образованных на очень пенепленизированной поверхности. Поэтому даже в нескольких метрах от коренного берега накапливались глинистый песок с галечками (до 5 мм). По мере заполнения водоема осадками и продолжающегося его осолонения, вдоль берегов возникли экологические зоны, благоприятные для существования устричных банок - биогерм. 
Возможно, что появление их знаменует начало ускорения трансгрессии, отмеченное в разрезе (слой 9, табл. 1) песком, очень глинистым с немногочисленными кусочками дресвы карбонатных пород. Далее на эту поверхность без размыва и без прослоев пляжевых галечниковых песков, но вполне согласно, ложатся дюнные пески. Такая последовательность напластований указывает, скорее всего, не на регрессию моря в целом, а на общий тектонический подъем чокракской антиклинальной складки. Этот подъем через некоторое время сменился изменением уклона склона на западной периклинали структуры, о чем свидетельствует слой 7 (табл. 1). Действительно, выстилание поверхности эрозионного несогласия столь крупными обломками известняков чокракского времени, а вслед за этим событием образование галечникового тела (мощность $\approx 3$ м), вследствие продолжающейся трансгрессии, могли произойти только в том случае, если прежнее очень пологое погружение пенепленизированного склона под воды наступающего карангатского моря стало более крутым. А значит, крупные штормовые волны стали достигать коренного берега. Сохранность в разрезе трансгрессивного цикла геологических образований, свидетельствующих о перерыве в осадконакоплении, также свидетельствует в пользу предположения об изменении угла падения поверхности склона, а не о вертикальном его воздымании.

Основываясь на приведенных фактах можно утверждать:

- галечниковая терраса образована до окончания карангатский трансгрессии и, скорее всего, имеет возраст нижних слоев верхнего карангата;

- перерыв в морском осадконакоплении может быть истолкован как следствие тектонической активности чокракской антиклинали;

- ниже слоя с биогермами располагаются верхние слои нижнего карангата.

Однако эти суждения предварительные и вопросы, поднятые в данной статье, требуют дальнейшего исследования и обсуждения кругом заинтересованных исследователей.

В заключение хочу выразить благодарность Ю.И. Иноземцеву за консультации по данному вопросу в процессе подготовки публикации.

1. Архангельский А.Д., Страхов Н.М. Геологическое строение и история развития Черного моря. - М.; Л.: Изд-во АН СССР, 1938.

2. Федоров П.В. Стратиграфия четвертичных отложений Крымско-Кавказского побережья и некоторые вопросы геологической истории Черного моря. - М.: Изд-во АН СССР, вып. 88.

Institute of Geological Sciences NAS Ukraine, Kyiv, Ukraine Інститут геологічних наук НАН України, м. Київ, Україна
3. Шелкопляс В.Н., Христофорова Т.Ф. О строении морских четвертичных отложений Керченского региона // Геология и полезные ископаемые Мирового океана. 2007. - № 2. - С. 120-126.

4. Шнюков Е.Ф., Алёнкин В.М., Путь А.Л. и др. Геология шельфа УССР. Керченский пролив. - Киев: Наук. думка, 1981. - 160 с. 